\title{
Diversity of Ascidians from the Great Nicobar Biosphere Reserve (GNBR), India
}

\author{
G. Ananthan*, A.S. Prabhu, R. Sathishkumar, C. Stalin \\ Center for Advanced Study in Marine Biology, Faculty of Marine Sciences, Annamalai University, \\ Parangipettai- 608 502, Tamil Nadu, India \\ *casananthan@yahoo.co.in
}

\begin{abstract}
The Great Nicobar Biosphere Reserve nurtures a diverse amount of life and is very important to the biological diversity of India. Ascidians diversity has been recorded for the first time from the Great Nicobar Biosphere Reserve. In the present study, 15 species of ascidians were noticed in both intertidal and sub-tidal regions of GNBR, belonging to two orders, three suborders, six families and ten genera (Didemnum fulgens, Didemnum vexillum, Didemnum granulatum, Didemnum albidum, Didemnum candidum, Trididemnum cyanophorum, Diplosoma simile, Diplosoma spongiforme, Clavelina oblonga, Aplidium fuscum, Synoicum castellatum, Pycnoclavella diminuta, Ascidia virginea, Ascidiella aspersa and Styela sp.) during the year 2013-2014 of which, the Didemnidae family was recorded with the high diversity of 15 species. Species richness were highly recorded in Bquary Beach and lowly recorded from Campbell Bay. The present data suggests that GNBR coast offers a unique opportunity for future research on the ascidians diversity and ecology assessment.
\end{abstract}

Keywords: Ascidians, Biodiversity, GNBR 